\title{
Sekizinci Sınıf Öğrencilerinin Üstbilişsel Okuma Farkındalıkları ${ }^{1}$
}

\author{
DOI: 10.26466/opus.501825
}

\section{Zeynep Cetinkaya Edizer ${ }^{*}$ - Esin Özbilgin ${ }^{* *}$}

*Doç. Dr., İstanbul Üniversitesi-Cerrahpaşa, Hasan Ali Yücel Eğitim Fakültesi, İstanbul / Türkiye E-Posta: cetinkayazeynep@gmail.com ORCID:0000-0001-5449-5107

*Öğretmen, 50. Yıl Refet Bele Ortaokulu, Kartal / İstanbul / Türkiye E-Posta: esinaktasoglu@hotmail.com

ORCID:0000-0001-6779-3154

\section{Öz}

Bu çalı̧̧mada, sekizinci sınıfta okuyan öğrencilerin üstbilişsel okuma stratejilerini kullanma durumlarını belirlemek amaçlanmıştır. Araştırmanın çalışma grubu, İstanbul ili Kartal ilçesi 50. Yıl General Refet Bele Ortaokulu'nda eğitim alan 20 sekizinci sımı öğrencisinden oluşmaktadır. Çalışmada öğrencilerin üstbilişsel okuma farkındalıklarım belirlemek amacıyla görüşme yöntemi kullanılmıştır. 12 maddeden oluşan görüşme formu, öğrencilerin okuma öncesi, sırası ve sonrasina ilişkin üstbilişsel okuma farkındalıkların belirlemeye yönelik sorulardan oluşmaktadır. Bu sorulardan elde edilen verilerde, içerik analizi yapılmıştır. İçerik analizi için alanyazındaki kaynaklardan yararlanılarak 3 ana kategori ve 33 kod (strateji) listesi belirlenmiştir. Araştırmanın sonucunda; çalışma grubundaki öğrencilerin hem okuma öncesinde hem okuma sırasında hem de okuma sonrasinda üstbilişsel okuma stratejileri kullandıkları belirlenmiştir $(f=181)$. Ancak toplama bakıldığında $(f=660)$ bu stratejilerin kullanım sıklı̆̆ının az olduğu söylenebilir. Araştırmaya göre çalışma grubunun üstbilişsel okuma stratejilerinden en çok okuma sonrası $(f=72)$ stratejileri kullandıkları belirlenmiştir. Sonra strasıyla okuma öncesi $(f=60)$ ve okuma sırası $(f=48)$ üstbilişsel okuma stratejileri gelmektedir. Araştırma sonuçlarına bağh olarak üstbilişsel okuma sırası stratejileri işe koşacak çalışmalara öncelik verilmesi gerektĭg i belirtilebilir.

Anahtar Kelimeler: Okuma, üstbiliş, üstbilişsel okuma stratejileri.

\footnotetext{
${ }^{1}$ Bu çalışma İstanbul Üniversitesi Eğitim Bilimleri Enstitüsü Türkçe Eğitimi Bölümü "Sekizinci Sınıf Öğrencilerinin Üstbilişsel Okuma Becerileri Üzerine Bir Araştırma” adlı Yüksek Lisans Tezinin bir bölümüdür.
} 


\title{
Metacognitive Reading Awareness of The Eighth Grade Students
}

\begin{abstract}
In this study, it is aimed to determine the use of metacognitive reading strategies in eighth grade students. The study group consisted of 20 eighth grade students who were educated at from General Refet Bele Secondary School in the province of Kartal, İstanbul. In the study, interview method was used to determine the students' metacognitive reading awareness. The interview form, which consists of 12 items, consists of the questions about determining the metacognitive reading awareness of the students before, during and after reading. In the data obtained from these questions, content analysis was performed. For the content analysis, 3 main categories and 33 code (strategy) lists were determined by using the sources in the literature. As a result of the research; It was determined that the students in the study group used metacognitive strategies before, during and after reading $(f=181)$. However, when the total is examined $(f=660)$, it can be said that the frequency of these strategies is low. According to the study, it was determined that the study group used the most metacognitive strategies after reading $(f=72)$. Then, pre-reading $(f=60)$ and reading order $(f=48)$ metacognitive strategies respectively. Depending on the results of the research, it may be stated that the studies that will employ the reading order metacognitive strategies should be given priority.
\end{abstract}

Keywords: Reading, metacognition, metacognitive reading strategies. 


\section{Giriş}

Üstbiliş kavramını Flavell (1979), bilgileri bellekte depolama, tarama, izleme ve farkında olma şeklinde açıklamaktadır. Üstbiliş, "izleme, kontrol etme ve değerlendirme" süreçlerinden oluşmaktadır (Çakıroğlu, 2007, s.23). Üstbilişin bilgi, deneyim, hedef ve strateji olmak üzere dört bileşeni bulunmaktadır. Üstbiliş bilgisi, bireyin kendi öğrenme özellikleri, bilişsel stratejiler gibi bilgileri içerir. Deneyimler; ekleme, silme, düzenleme gibi bilinçli bilişsel yaşantılardan oluşur. Hedefler, bilişsel girişimin amaçlarıyla ilgilidir. Stratejiler ise hedefe ulaşmada etkili olan düşünce süreçlerinden oluşmaktadır (Aktürk ve Şahin, 2011, s.388-389).

Üstbilişi oluşturan bu bileşenler, zamanla üstbilişsel bilgi ve üstbilişsel kontrol şeklinde iki açıdan ele alınmıştır. Üstbilişsel bilgi; yordam bilgisi, bildirimsel bilgi ve duruma dayalı bilgiden oluşmaktadır. Yordam bilgisi, bir işin nasıl yapılacağını, nasıl sonuca erdirileceğini, nasıl başarıya ulaşılacağını bilmektir. Bildirimsel bilgi, bireyin yapmak için yeterli yetenek ve beceriye sahip olma açısından kendisini tanımasıyla ilgiliyken Duruma dayalı bilgi ise ne zaman, nerede, ne yapabileceğini ya da yapamayacağını bilmesidir (Özsoy, 2008).

Üstbilişsel kontrol ise üstbilişsel bilgiyi stratejik olarak kullanmayı sağlayan zihinsel işlem ve süreçlerdir. Üstbilişsel kontrolün dört basamağ1 vardır: tahmin, planlama, izleme ve değerlendirme. Tahmin etme kişinin öğrenmeye ilişkin amaçlarını, sürecini ve sonuçta ortaya çıkacak kazanımları sorgulamasını sağlar. Planlama, tahmin basamağından sonra gelir ancak tahmin etme adımında ortaya çıkan cevaplara göre şekillenir. Buna göre planlama adımında işe yarar stratejiler seçilir ve gerekli araçlar belirlenir. İzleme adımı öğrenme gerçekleştikten sonra sürece yönelik analiz yapılan adımdır. İzlemede birey tahmin etme ve planlama doğrultusunda gerçekleştirdiği eylemleri inceler ve çıkarımlarda bulunur. Buna göre doğru yaptıklarını ve yapmaması gerekenleri belirleyebilir. $\mathrm{Bu}$ çıkarımlar sonraki süreçler için önem taşır (Schraw ve Moshman, 1995). Üstbilişsel kontrolün son aşaması olan değerlendirme adımında kişi öğrenmenin verimine ve elde ettiği bilgilerin niteliğine göre yargıda bulunur (Özsoy, 2008).

Okuma, öğrenmenin en temel araçlarından biridir ancak okumanın 
kendisi sadece bir araç değil başlı başına bir süreçtir. Okuyucunun bu süreçten en yüksek verimi alması, belli stratejiler kullanmasını gerekli kılmaktadır. Okuma stratejileri "kişinin okuma eylemi süresince bilinçli olarak yaptığı işlemleri içerir" (Karatay, 2011, s.46). Üstbilişsel okuma stratejileri "planlama, izleme ve değerlendirme" olmak üzere üç aşamada gerçekleşir (Baker ve Brown, 1984). Alanyazında bu stratejiler; okuma öncesi, okuma sırası ve okuma sonrası şeklinde de ele alınmaktadır Okuma öncesinde kullanılan stratejiler; okuma amacını belirleme, okuma türünü ve hızını saptama, metni gözden geçirme, metnin başlıklarına bakma, metnin uzunluğunu gözden geçirme, tahmin etme, sorular sorma gibi okumanın planlanmasına yönelik stratejilerdir. Okurken not tutma, dikkatli okuma, tekrar okuma, işaretleme yapma, kaynak kullanma, tahmin etme, ipuçlarından yararlanma, dilbilgisel ilişkileri kestirme, biçimsel şemadan yararlanma, okuduklarını denetleme gibi stratejiler okuma sırasında kullanılan stratejilerdir. Okuma sonrası stratejiler ise metni sorgulama, kontrol etme, özetleme, tekrar okuma, eleştirme, tartışma, soruları yanıtlama gibi okuduklarını değerlendirmeye yönelik stratejilerdir (Karatay, 2011; Ülper, 2010).

Okuma, öğrenmeyi sağlayan yöntemlerin en başta gelenidir. Öğrenmenin verimini yükseltmek için üstbilişsel stratejileri etkin bir şekilde kullanabilmek önemlidir. Öğrencilerin kendi okuma ve öğrenme süreçlerini planlamaları, izlemeleri ve değerlendirmelerini içeren üstbilişsel stratejiler bu nedenle son yıllarda okuma araştırmalarında öne çıkan bir kavramdır (Jacopson, 1998).

Alanyazında okurların kullandıkları üstbilişsel okuma stratejilerini belirlemeye yönelik çeşitli çalışmalar bulunmaktadır. McGuire ve Yewchuk (1996) özel yetenekli ilkokul öğrencilerinin üstbilişsel okuma stratejilerinde yeterli olmadıklarını belirlemişlerdir. Berkowitz ve Cicchelli (2004) ortaokul öğrencileriyle yaptıkları çalışmada başarılı ve başarısız öğrencilerin kullandıkları stratejilerin birbirine benzer ve orta düzeyde olduğu sonucuna ulaşmışlardır. Karatay (2007) Türkçe öğretmeni adaylarının üstbilişsel okuma stratejilerini kullanım düzeylerinin orta seviyede olduğunu belirtmiştir. Okuma stratejilerinin en az kullanıldığı sürecin okuma sonrası süreç olduğu bulgusuna erişmiştir. Çöğmen (2008) eğitim fakültesi öğrencilerinin okuduğunu anlama stratejileri kullanım düzeyini "sık sık kullanırım" düzeyinde bulmuştur. 
Öğrencilerin akademik başarıları ile okuma stratejilerini kullanma sıklıkları arasında olumlu ve anlamlı ilişki olduğunu belirtmiştir. Hannah ve Shore (2008), on bir ve on ikinci sınıf üstün yetenekli öğrencilerin izleme ve değerlendirme stratejilerini daha çok kullandıklarını belirlemişlerdir. Topuzkanamış (2009), öğretmen adaylarının okuma stratejilerini kullanımının orta düzeyde olduğunu ifade etmiştir. Ayrıca akademik başarı puanı ve okuduğunu anlama arasında düşük ama anlamlı bir ilişki bulmuştur. Anastasiou ve Griva (2009) altıncı sınıf öğrencileri ile yürüttükleri çalışmada başarılı okuyucuların daha az başarılı okuyuculara göre üstbilişsel okuma stratejilerini daha sık kullandıklarını belirlemişlerdir. Karatay (2010) altı, yedi ve sekizinci sınıf öğrencilerinin, üstbilişsel okuma stratejilerinden planlamada iyi, düzenleme ve değerlendirmede orta düzeyde olduklarını bulgulamıştır. Başaran (2013), dördüncü sınıf öğrencilerinin üstbilişsel okuma stratejilerini sıklıkla kullandıklarını ifade etmiştir. Çetinkaya Edizer (2015) başarılı ve daha az başarılı olan Türkçe öğretmeni adaylarının en çok izleme/düzenleme stratejilerini kullandıkları sonucuna ulaşmıştır. Başarılı öğrencilerin üstbilişsel strateji kullanım sıklığı, daha az başarılı öğrencilerden fazladır. Fitrisia, Tan ve Yusuf (2015), lise öğrencileri ile yaptıkları çalışmada üstbilişsel okuma stratejilerinin anlama konusunda önemli bir rolü olduğu sonucuna varmışlardır. Bahar (2017), 4MAT öğretim düzenine göre verilen üstbilişsel okuma eğitimin geleneksel öğretim düzenine göre verilen eğitimden daha yararlı olduğunu; deney grubunun planlama, izleme ve değerlendrme alt boyutlarında başarılarını anlamlı bir biçimde artırdığını bulgulamıştır. Özdemir (2018) ise öğretmen adaylarının üstbilişsel okuma stratejilerini sık kullandıklarını belirtmiştir.

Okuma etkinliklerinin temeldeki amacı anlama ve öğrenmedir. Strateji kullanımı da anlamı oluşturmada etkili bir unsurdur. Öğrencilerin kullandıkları üstbilişsel okuma stratejilerini belirlemek, anlamsal yap1 oluşturmanın ne derece gerçekleştiğini belirlemek açısından önemlidir. Bu araştırmada da sekizinci sınıfta okuyan öğrencilerin üstbilişsel okuma stratejilerini kullanma durumlarını görüşme yoluyla belirlemek amaçlanmıştır. Bu amaç doğrultusunda "Sekizinci sınıf öğrencilerinin kullandıkları üstbilişsel okuma strateji türleri ve kullanım sıklığı nedir?" sorusuna yanıt aranmıştır. 


\section{Yöntem}

Sekizinci sınıf öğrencilerinin üstbilişsel okuma stratejilerini kullanma durumlarını belirlemeyi amaçlayan çalışma, betimsel bir araştırmadır. Nitel araştırma yönteminin benimsendiği bu araştırmada veriler, görüşme yoluyla elde edilmiştir. "Görüşme belirli bir araştırma konusu veya bir soru hakkında derinlemesine bilgi sağlar" (Büyüköztürk, Kılıç Çakmak, Akgün, Karadeniz ve Demirel, 2014, s.150). Araştırmada standartlaştırılmış açık uçlu görüşme kullanılmıştır. Böylelikle görüşmecinin yanlı ve öznel davranma olasılığı azaltılmaya çalışılmıştır (Yıldırım ve Şimşek, 2013, s.151). Standartlaştırmada sorular ve bunların sırası önceden belirlenir (Merriam, 2013, s.87). Bu nedenle çalışmada üstbilişsel okuma strateji kullanımına yönelik sorular hazırlanmış, bu sorular okuma öncesi, sırası ve sonrası açısından belli bir sıraya konmuş ve görüşülen her bireye sorular aynı sırada sorulmuştur.

\section{1. Çalışma Grubu}

Araştırmanın çalışma grubu, İstanbul ili Kartal ilçesi 50. Yıl General Refet Bele Ortaokulu'nda 2016-2017 eğitim-öğretim yılında eğitim alan 20 sekizinci sınıf öğrencisinden oluşmaktadır. Üstbilişsel okuma stratejilerini belirlemeye yönelik alanyazın çalışmalarında da Yaylı (2010) 12; Özek ve Civelek (2006) 23 ve Çetinkaya Edizer (2015) 10 katılımcı ile çalışmalarını yürütmüşlerdir. Bu çalışmada öğrencilere Ö1, Ö2, Ö3 şeklinde kodlama yapılmıştır. Örneklem belirlenirken amaçlı örnekleme çeşitlerinden "kolay ulaşılabilir durum örneklemesi" seçilmiştir. Bu çeşit örneklem araştırmacıya "hız ve pratiklik" sağlar (Yıldırım ve Şimşek, 2013, s. 141).

\subsection{Verilerin Toplanması}

Araştırmada veriler, öğrencilerin üstbilişsel okuma farkındalıklarını belirlemeye yönelik sorulardan oluşan görüşme formu ile elde edilmiştir. Bu form, Mokhtari ve Reichard (2002) tarafından geliştirilen ve Türkçe formu geçerlik ve güvenirlik çalışması Öztürk (2012) tarafından yapılan Okuma Stratejileri Üstbilişsel Farkındalık Envanteri (OSÜFE) temel alınarak oluşturulmuştur. Yararlanılan ölçeğin Türkçe ve İngilizce formlarından 
elde edilen puanlar arasındaki korelasyon .96; ölçeğe ait faktörler .76 ve .85 arası güvenirlik değerine sahiptir. Ölçekte insanların akademik ya da okulla ilgili metinleri okurken yaptıkları hakkında "Okurken zihnimde bir amaç vardır. Okurken, okuduğumu anlamak için notlar alırım. Okuduğumu anlamama yardım edecek neler biliyorum diye düşünürüm." gibi ifadelere yer verilmiştir.

Ölçeğe bağlı olarak oluşturulan görüşme formu hakkında kapsam geçerliği için ölçme değerlendirme ve alan uzmanından görüşler alınmıştır. Formun son şekli, görünüş geçerliği açısından uzmanlara tekrar gösterilmiştir. Güvenirlik için çalışma grubundaki dört öğrenciye çalışmanın bulguları gösterilmiştir. Araştırma sırasında görüşme formu, bireysel olarak doldurulmuştur. Öğrencilerin görüşme sorularına yanıt vermeleri 20-25 dakika sürmüştür. 12 maddeden oluşan görüşme formunun maddeleri aşağıda verilmiştir:

1. Okumadan önce zihninizde bir amaç var mıdır? Açıklar mısınız?

2. Okuyacağınız bir metni gözden geçirir misiniz? Açıklar mısınız?

3. Okuma hızınızı ayarlarken nelere dikkat edersiniz? Açıklar misiniz?

4. Eski bilgilerinizle metin arasında ilişki kurmaya çalışır mısınız? Açıklar mısınız?

5. Bilmediğiniz sözcüklerin ya da cümlelerin anlamlarını bağlamdan bulmaya çalışır mısınız? Açıklar mısınız?

6. Anlamakta zorlandığınız bir metinle karşılaştığınızda neler yaparsınız? Açılar mısınız?

7. Okuduktan sonra metne ilişkin bilgi ve düşünceler arasında bağlantı kurmaya çalışır mısınız? Açıklar mısınız?

8. Okuma sırasında ya da sonrasında ana düşünceyi belirlemeye çalışır mısınız? Açıklar mısınız?

9. Okuduğunuz bir metni kendi sözcüklerinizle ya da resim, grafik, tablo gibi şekillerle yeniden yorumlar mısınız? Açıklar mısınız?

10. Okuduklarınızı başkalarıyla konuşarak tartışır mısınız? Açıklar misiniz?

11. Okuduklarınıza ilişkin araştırma yapar mısınız? Açıklar mısınız?

12. Okuduklarınızı günlük hayatla ilişkilendirir misiniz? Açıklar misiniz? 


\subsection{Verilerin Çözümlenmesi}

Verilerin çözümlenmesinde içerik analizi yapılmıştır. İçerik analizi, anlamı sinıflandırarak ifade etmedir (Bilgin, 2000). Bu analiz çeşidinde verilerin incelenmesi için bir kod listesi oluşturulur. Bu kodlar bir araya getirilerek kategoriler belirlenir (Yıldırım ve Şimşek, 2013). Bu çerçevede çalışmada, alanyazın incelenerek bir kod listesi hazırlanmıştır (Karatay, 2011; Öztürk, 2012). Verilerden çıkan yeni kodlar da listeye eklenmiştir. Oluşturulan kod listesi, Tablo 1'de gösterilmiştir.

Belirlenen kodlar, üstbilişsel okuma stratejilerine yöneliktir. Hazırlanan görüşme sorularının bu kodlarla eşleştirilmesi, Tablo 2'de sunulmuştur.

Görüşme formunun analizi, araştırmacı ve uzman tarafından yapılmıştır. Analiz için öncelikle iki araştırmacı her bir katılımcının verdiği yanıtları tek başına üstbilişsel okuma stratejilerine göre kodlamışlardır. $\mathrm{Bu}$ aşamadan sonra araştırmacıların vermiş oldukları yanıtlar 1 ve 0 şeklinde kodlanmıştır. Üstbilişsel okuma stratejisi varsa 1 numara yoksa 0 numara verilmiştir. 1 ve 0 şeklindeki değerlerin ortak ve farklı yönlerine bakılmıştır. 25 kod her iki araştırmacı tarafından ortak olarak verilmiştir. 7 koda her iki araştırmacı da puan vermemiştir. Hazırlanan tablolar neticesinde ortak karar yüzdesi hesaplanmıştır. Bu hesaplamada gözlenen ortak karar yüzdesi 7/33 + 25/33 = 0,9696 olarak bulunmuştur. Diğer bir ifadeyle kodlamalar arasında \%96 oranında uyumluluk vardır. $\mathrm{Bu}$ analizin sonucunda verilerin frekans değerleri hesaplanmıştır.

Tablo 1. Üstbilişsel Okuma Stratejileri İçerik Kodları

\begin{tabular}{|c|c|}
\hline Okuma Stratejileri & İçerik Kodları \\
\hline \multirow{10}{*}{ 1. Okuma Öncesi Stratejiler } & 1. Amaç belirleme \\
\hline & 2. Konusunu anlamak için gözden geçirme \\
\hline & 3. Önceki bilgilerden yararlanma \\
\hline & 4. Başlık, alt başlık ve yazara bakma \\
\hline & 5. Uzunluğunu anlamak için gözden geçirme \\
\hline & 6. Nelere odaklanacağına karar verme \\
\hline & 7. Tahmin etme \\
\hline & 8. Sorular sorma \\
\hline & 9. Okuma hızını belirleme \\
\hline & 10. Var olan görselleri yorumlama \\
\hline
\end{tabular}




\begin{tabular}{ll}
\hline & \multicolumn{1}{l}{ 1. Not alma } \\
\hline 2. Okuma hızını ayarlama \\
\hline 3. Dikkatini toplayarak tekrar okuma \\
\hline 4. İşaretleyerek okuma \\
\hline 5. Sözlük, internet, başkasına sorma vb. yollarla bilgi \\
edinme
\end{tabular}

Tablo 2. Görüşme Sorularının Kodlarla Eşleştirilmesi

\begin{tabular}{|c|c|}
\hline Sorular & Kod Listesi \\
\hline $\begin{array}{l}\text { 1. Okumadan önce zihninizde bir amaç var } \\
\text { mıdır? Açıklar mısınız? }\end{array}$ & 1.1. Amaç belirleme \\
\hline $\begin{array}{l}\text { 2. Okuyacağıını bir metni gözden geçirir } \\
\text { misiniz? Açılar mısınız? }\end{array}$ & $\begin{array}{l}\text { 1.2. Konusunu anlamak için gözden geçirme } \\
\text { 1.4. Başlık, alt başlık ve yazara bakma } \\
\text { 1.5. Uzunluğunu anlamak için gözden geçirme } \\
\text { 1.6. Nelere odaklanacağına karar verme } \\
\text { 1.7.Tahmin etme } \\
\text { 1.8. Sorular sorma } \\
\text { 1.10. Var olan görselleri yorumlama }\end{array}$ \\
\hline $\begin{array}{l}\text { 3. Okuma hızınızı ayarlarken nelere dikkat } \\
\text { edersiniz? }\end{array}$ & 1.9. Okuma hızını belirleme \\
\hline $\begin{array}{l}\text { 4. Eski bilgilerinizle metin arasında ilişki } \\
\text { kurmaya çalışır mısınız? }\end{array}$ & 1.3. Önceki bilgilerden yararlanma \\
\hline $\begin{array}{l}\text { 5. Bilmediğiniz sözcüklerin ya da cüm- } \\
\text { lelerin anlamlarını bulmaya çalışır mısınız? }\end{array}$ & $\begin{array}{l}\text { 2.5. Sözlük, internet, başkasına sorma vb. yol- } \\
\text { larla bilgi edinme }\end{array}$ \\
\hline $\begin{array}{l}\text { 6. Anlamakta zorlandığınız bir metinle } \\
\text { karşılaştığınızda neler yaparsınız? }\end{array}$ & $\begin{array}{l}\text { 2.1. Not alma } \\
\text { 2.2. Okuma hizını ayarlama }\end{array}$ \\
\hline
\end{tabular}




\begin{tabular}{|c|c|}
\hline & $\begin{array}{l}\text { 2.3. Dikkatini toplayarak tekrar okuma } \\
\text { 2.4. İşaretleyerek okuma } \\
\text { 2.6. Metin üzerinde yoğunlaşma } \\
\text { 2.7. Yüksek sesle okuma } \\
\text { 2.8. Düşünmek için ara verme } \\
\text { 2.9. İçerik ipuçlarını kullanma } \\
\text { 2.11. Çelişen bilgileri gözden geçirme } \\
\text { 2.12. Anlamı tahmin ederek bulma }\end{array}$ \\
\hline $\begin{array}{l}\text { 7. Okuduktan sonra metne ilişkin bilgi ve } \\
\text { düşünceler arasında bağlantı kurmaya } \\
\text { çalışır mısınız? }\end{array}$ & $\begin{array}{l}\text { 3.1. İçerik-Amaç uyumunu sorgulama } \\
\text { 3.4. Metni okumayı bitirdikten sonra gözden } \\
\text { geçirme } \\
\text { 3.5. Metni yeniden okuma } \\
\text { 3.6. Tahminlerinin doğruluğunu kontrol etme } \\
\text { 3.7. Metindeki bilgileri eleştirerek değer- } \\
\text { lendirme }\end{array}$ \\
\hline $\begin{array}{l}\text { 8. Okuma sırasında ya da sonrasında ana } \\
\text { düşünceyi belirlemeye çalışır mısınız? }\end{array}$ & 3.8. Ana düşünceyi belirleme \\
\hline $\begin{array}{l}\text { 9. Okuduğunuz bir metni kendi sözcükleri- } \\
\text { nizle ya da resim, grafik, tablo gibi } \\
\text { şekillerle yeniden yorumlar mısınız? }\end{array}$ & 3.3. Özetleme \\
\hline $\begin{array}{l}\text { 10. Okuduklarınızı başkalarıyla konuşarak } \\
\text { tartışır mısınız? }\end{array}$ & 3.9. Metin hakkında başkalarıyla tartışma \\
\hline $\begin{array}{l}\text { 11. Okuduklarınıza ilişkin araştırma yapar } \\
\text { mısınız? }\end{array}$ & 3.10. Metinle ilgili araştırma yapma \\
\hline $\begin{array}{lrll}12 . & \text { Okuduklarınızı } & \text { günlük hayatla } \\
\text { ilişkilendirir misiniz? } & & \end{array}$ & $\begin{array}{l}\text { 3.2. Metindeki bilgiyi günlük hayatla } \\
\text { ilişkilendirme }\end{array}$ \\
\hline
\end{tabular}

\section{Bulgular}

$\mathrm{Bu}$ bölümde görüşme formundan elde edilen bulgular okuma öncesinde, sırasında ve sonrasında kullanılan stratejiler olarak alt başlıklarda irdelenerek verilmiştir. Üstbilişsel okuma öncesi stratejilerine ait bulgular, Tablo 3'te sunulmuştur.

Görüşme verilerinden elde edilen sonuçlara bakıldığında katılımcların okuma öncesinde en sık amaç belirleme stratejisini kullandıkları görülmektedir ( $\mathrm{f}=15$ ). İkinci sırada sık kullanılan strateji önceki bilgilerden yararlanma stratejisidir $(\mathrm{f}=12)$. 
Tablo 3. Üstbilişsel Okuma Öncesi Stratejilerine İlişkin Bulgular

\begin{tabular}{|c|c|c|}
\hline Strateji Türü & $\mathbf{f}$ & Örnek Cümleler \\
\hline 1. Amaç belirleme & 15 & $\begin{array}{l}\text { Kitabı okumaya başlamadan önce bana bir şeyler katmasını, } \\
\text { okudukça okuma isteğimin artmasını ve eğlenebilmeyi } \\
\text { amaçlarım. (Ö11) }\end{array}$ \\
\hline $\begin{array}{l}\text { 2. Konusunu anla- } \\
\text { mak için gözden } \\
\text { geçirme }\end{array}$ & 7 & $\begin{array}{l}\text { Okumadan önce metnin nasıl olup olmadığına bakarım. } \\
\text { Yabancı kelimelere filan bakarım. (Ö14) }\end{array}$ \\
\hline $\begin{array}{l}\text { 3. Önceki bilgilerden } \\
\text { yararlanma }\end{array}$ & 12 & $\begin{array}{l}\text { Çünkü o bildiklerim o metinle ilişkili ise bu metni anlamama } \\
\text { yardımcı olur. (Ö13) }\end{array}$ \\
\hline $\begin{array}{l}\text { 4. Başlık, alt başlık } \\
\text { ve yazara bakma }\end{array}$ & 5 & $\begin{array}{l}\text { Özetlerine bakarım, yaşıma uygun olup olmadığına bakarım, } \\
\text { sayfa sayısına ve yazarına bakarım. (Ö8) }\end{array}$ \\
\hline $\begin{array}{l}\text { 5. Uzunluğunu anla- } \\
\text { mak için gözden } \\
\text { geçirme }\end{array}$ & 4 & Okumadan önce bütün yapraklarına bakarım (Ö17) \\
\hline $\begin{array}{l}\text { 6. Nelere odaklana- } \\
\text { cağına karar verme }\end{array}$ & 2 & $\begin{array}{l}\text { Okumadan önce başlı̆̆ına, resmi varsa resimlerine ve metne } \\
\text { baştan aşağ } 1 \text { bakıp anahtar kelimeleri incelerim. (Ö2) }\end{array}$ \\
\hline 7.Tahmin etme & 4 & $\begin{array}{l}\text { Resimlerine bakarım, tahmin etmeye çalışırım ve genelde } \\
\text { yazarların isimlerine bakarım. (Ö11) }\end{array}$ \\
\hline 8. Sorular sorma & 0 & - \\
\hline $\begin{array}{l}\text { 9. Okuma hızını be- } \\
\text { lirleme }\end{array}$ & 5 & $\begin{array}{l}\text { Kısa metinler olursa kalem ile çizerek okumam metni okuma } \\
\text { süremi ve metni anlamamı daha çok etkiler. Fakat bu bir ro- } \\
\text { man vb. olursa daha sakin bir ortamda okumak isterim çünkü } \\
\text { daha iyi anlarım. (Ö1) }\end{array}$ \\
\hline $\begin{array}{l}\text { 10. Var olan görsel- } \\
\text { leri yorumlama }\end{array}$ & 6 & $\begin{array}{l}\text { Yeni alacağım bir kitapta da arka yüzünü okurum. Ayrıca } \\
\text { kitabın ön kapağını da incelerim. Metinlerde de resimleri } \\
\text { incelerim. (Ö7) }\end{array}$ \\
\hline
\end{tabular}

Bulgulara göre çalışma grubu sirasıyla konusunu anlamak için gözden geçirme $(\mathrm{f}=7)$, var olan görselleri yorumlama $(\mathrm{f}=6)$, başlık, alt başlık ve yazara bakma ( $\mathrm{f}=5)$, okuma hızını belirleme $(\mathrm{f}=5)$, uzunluğunu anlamak için gözden geçirme $(\mathrm{f}=4)$, tahmin etme $(\mathrm{f}=4)$ ve nelere odaklanacağına karar verme $(\mathrm{f}=2)$ stratejilerini kullandıklarını belirtmişlerdir. Sorular sorma stratejisini ise kullandıklarını belirtecek hiçbir ifade kullanmamışlardır ( $\mathrm{f}=0$ ).

Üstbilişsel okuma sırası stratejilerine yönelik bulgular, Tablo $4^{\prime}$ te sunulmuştur.

Çalışma grubundakiler, okuma sırası stratejilerinden en çok sözlük, internet, başkasına sorma vb. yollarla bilgi edinme $(\mathrm{f}=18)$ ve okuma hızını ayarlama $(\mathrm{f}=13)$ stratejilerini kullandıklarını belirtmişlerdir. Görsellerle anlatma $(\mathrm{f}=7)$ ve dikkatini toplayarak tekrar okuma $(\mathrm{f}=6)$ stratejileri ise daha az kullanılan stratejilerdir. 
Tablo 4. Üstbilişsel Okuma Strası Stratejilerine İlişkin Bulgular

\begin{tabular}{|c|c|c|}
\hline Strateji Türleri & $\mathbf{f}$ & Örnek Cümleler \\
\hline 1. Not alma & 1 & $\begin{array}{l}\text { Anlamadı̆̆ım kelimeleri not ederim ve sözlükten bakarım. } \\
\text { (Ö12) }\end{array}$ \\
\hline $\begin{array}{l}\text { 2. Okuma hizını ayar- } \\
\text { lama }\end{array}$ & 13 & $\begin{array}{l}\text { Okurken zor anlayabileceğim bir şey ise yavaş, kolay an- } \\
\text { layabileceğim bir şey ise hizlı okurum. (Ö9) }\end{array}$ \\
\hline $\begin{array}{l}\text { 3. Dikkatini toplayarak } \\
\text { tekrar okuma }\end{array}$ & 6 & $\begin{array}{l}\text { Sessiz bir ortama geçerim ve birkaç defa daha okurum. } \\
\text { (Ö11) }\end{array}$ \\
\hline 4. İşaretleyerek okuma & 0 & - \\
\hline $\begin{array}{l}\text { 5. Sözlük, internet, } \\
\text { başkasına sorma vb. yol- } \\
\text { larla bilgi edinme }\end{array}$ & 18 & $\begin{array}{l}\text { Bilmediğim bir ya da birden fazla kelime varsa bunları bul- } \\
\text { maya çalışırım. Sözlükten araştırarak bulurum ya da } \\
\text { başkalarına sorarım. (Ö6) }\end{array}$ \\
\hline $\begin{array}{l}\text { 6. Metin üzerinde yoğun- } \\
\text { laşma }\end{array}$ & 0 & - \\
\hline 7. Yüksek sesle okuma & 0 & - \\
\hline $\begin{array}{l}\text { 8. Düşünmek için ara } \\
\text { verme }\end{array}$ & 1 & $\begin{array}{l}\text { O kitabı okumayı bırakırım. Biraz dinlendikten sonra } \\
\text { tekrar okumaya başlarım. Ama bilmediğim çok kelime } \\
\text { olursa da kitabı okumayı tekrar bırakırım. İleri zamanlarda } \\
\text { okurum. (Ö8) }\end{array}$ \\
\hline $\begin{array}{l}\text { 9. İçerik ipuçlarını } \\
\text { kullanma }\end{array}$ & 0 & - \\
\hline 10. Görsellerle anlatma & 7 & $\begin{array}{l}\text { Okuduktan sonra daha iyi anlayabilmek için kendim metni } \\
\text { özetleyerek resim şeklinde yapabilirim. (Ö6) }\end{array}$ \\
\hline $\begin{array}{l}\text { 11. Çelişen bilgileri } \\
\text { gözden geçirme }\end{array}$ & 1 & $\begin{array}{l}\text { Eğer kurmam çok gerekirse yani metin çok çelişkiliyse } \\
\text { bilgilerimle karşılaştırırım. (Ö3) }\end{array}$ \\
\hline $\begin{array}{l}\text { 12. Anlamı tahmin } \\
\text { ederek bulma }\end{array}$ & 1 & $\begin{array}{l}\text { Tahmin edebileceğim kadar kolaysa bakmam. Onun ha- } \\
\text { ricinde bakarım. (Ö2) }\end{array}$ \\
\hline $\begin{array}{l}\text { 13. Metinde ileri geri } \\
\text { ilişki kurma }\end{array}$ & 0 & - \\
\hline
\end{tabular}

Okuma sırası stratejilerinden not alma, düşünmek için ara verme, çelişen bilgileri gözden geçirme, anlamı tahmin ederek bulma stratejileri çok az ( $\mathrm{f}=1)$ kullanılmış; işaretleyerek okuma, metin üzerinde yoğunlaşma, yüksek sesle okuma, içerik ipuçlarını kullanma, metinde ileri geri ilişki kurma stratejileri ise hiç kullanılmamıştır ( $\mathrm{f}=0)$.

Üstbilişsel okuma sonrası strateji bulguları, Tablo 5 'te verilmiştir.

Okuma sonrası stratejilerde, sirasiyla metinle ilgili araştırma yapma $(\mathrm{f}=17)$, ana düşünceyi belirleme $(\mathrm{f}=14)$, metindeki bilgiyi günlük hayatla ilişkilendirme $(\mathrm{f}=13)$, metin hakkında başkalarıla tartışma ( $\mathrm{f}=12)$ ve metni yeniden okuma ( $\mathrm{f}=9$ ) stratejilerinin daha çok kullanıldığı belirlenmiştir. 
Tablo 5. Üstbilişsel Okuma Sonrası Stratejilerine İlişkin Bulgular

\begin{tabular}{lcl}
\hline \multicolumn{1}{c}{ Strateji Türleri } & f & \multicolumn{1}{c}{ Örnek Cümleler } \\
\hline $\begin{array}{l}\text { 1. İçerik-amaç uyumunu } \\
\text { sorgulama }\end{array}$ & 0 & -
\end{tabular}

Özetleme (f=4), tahminlerinin doğruluğunu kontrol etme ( $\mathrm{f}=2$ ) ve metni okumayı bitirdikten sonra gözden geçirme ( $\mathrm{f}=1)$ stratejileri çok az ifade edilmiştir. İçerik amaç uyumunu sorgulama ve metindeki bilgileri eleştirerek değerlendirme stratejileri ise hiçbir öğrenci tarafından belirtilmemiştir ( $\mathrm{f}=0$ ).

Okuma öncesi, sırası ve sonrası kullanılan üstbilişsel stratejilerin toplam kullanım sıklıkları bütünlük oluşturma açısından, Tablo 6'da sunulmuştur.

Tablo 6. Üstbilişsel Okuma Stratejilerine İlişkin Bulgular

\begin{tabular}{lcc}
\multicolumn{1}{c}{ Strateji } & Maksimum (f) & $\sum \mathbf{f}$ \\
\hline Okuma Öncesi Stratejiler & 200 & 60 \\
\hline Okuma Sırası Stratejiler & 260 & 48 \\
\hline Okuma Sonrası Stratejiler & 200 & 72 \\
\hline$\sum \mathbf{f}$ & 660 & 181 \\
\hline
\end{tabular}


Tablo 6'ya göre çalışma grubunun sirasıyla okuma sonrası ( $\mathrm{f}=72)$, okuma öncesi $(\mathrm{f}=60)$ ve okuma sırası $(\mathrm{f}=48)$ üstbilişsel stratejileri kullandıkları görülmektedir. Her üç aşamada strateji kullanım ifadeleri $(\mathrm{f}=181)$ belirlense de toplama bakıldığında $(\mathrm{f}=660)$ çalışma grubunun üstbilişsel okuma stratejilerini az kullandıkları belirtilebilir.

\section{Tartışma ve Sonuç}

Araştırmada, sekizinci sınıfta okuyan öğrencilerin üstbilişsel okuma stratejilerini kullanma durumlarını belirleme amaçlanmıştır. Bu amaç doğrultusunda yapılan araştırmada, çalışma grubunun okuma öncesi, sırası ve sonrası olmak üzere her üç aşamada üstbilişsel stratejiler kullandıkları belirlenmiştir ( $\mathrm{f}=181)$. Ancak toplama bakıldığında $(\mathrm{f}=660)$ çalışma grubunun üstbilişsel okuma strateji kullanım sıklığının az olduğu ifade edilebilir. Alanyazında yapılan çalışmalarda da ilkokul (McGuire ve Yewchuk, 1996), ortaokul (Berkowitz ve Cicchelli, 2004) ve öğretmen adaylarının (Çetinkaya Edizer, 2015; Karatay, 2007; Topuzkanamış, 2009) üstbilişsel okuma stratejilerini kullanım sıklıkları genelde orta ya da düşük düzeyde bulunmuştur. Farklı düzeylerdeki bu bulgulara bağlı olarak strateji kullanımının yeterli düzeyde olmadığı belirtilebilir.

Araştırmaya göre çalışma grubunun üstbilişsel stratejilerden en çok okuma sonrası ( $\mathrm{f}=72)$ stratejileri kullandıkları belirlenmiştir. Bunu sırasıyla okuma öncesi $(\mathrm{f}=60)$ ve okuma sırası $(\mathrm{f}=48)$ stratejileri izlemektedir. Alanyazında bu durumla ilgili farklı sonuçlar bulunmaktadır. Hannah ve Shore (2008), on bir ve on ikinci sınıf üstün yetenekli öğrencilerin okuma sırası ve sonrası (izleme ve değerlendirme); Karatay (2010) altı, yedi ve sekizinci sınıf öğrencilerinin okuma öncesi (planlama); Çetinkaya Edizer (2015) de Türkçe öğretmen adaylarının okuma sırası (izleme/düzenleme) stratejilerini daha sık kullandıkları sonucuna ulaşmışlardır.

Araştırmadaki çalışma grubu, okuma öncesinde en çok amaç belirleme stratejisini kullanmıştır ( $\mathrm{f}=15$ ). Amaç belirleme, yapılacak üstbilişsel işlemlerin karar verilmesinde ilk aşamayı oluşturan önemli bir stratejidir. Okuma öncesi stratejilerinden sık kullanılanlardan biri de önceki bilgilerden yararlanma stratejisidir ( $\mathrm{f}=12$ ). Yapılandırmacı yaklaşımın öğretim pro- 
gramlarına girmesiyle beraber öğretimde önceki bilgilerden yararlanmanın önemi artmıştır. Katılımcıların da bu durumu içselleştirdikleri belirtilebilir.

Bulgulara göre çalışma grubu okuma öncesinde yer alan konusunu anlamak için gözden geçirme $(\mathrm{f}=7)$, var olan görselleri yorumlama $(\mathrm{f}=6)$, başlık, alt başlık ve yazara bakma $(\mathrm{f}=5)$, okuma hızını belirleme $(\mathrm{f}=5)$, uzunluğunu anlamak için gözden geçirme $(\mathrm{f}=4)$, tahmin etme $(\mathrm{f}=4)$ ve nelere odaklanacă̆ına karar verme $(\mathrm{f}=2)$ stratejilerini daha az kullandıklarını belirtmişlerdir. $\mathrm{Bu}$ stratejiler az kullanılsa da çalışma grubundakilerin okuma öncesinde zihinlerinde bir hazırlık oluşturmaya çalıştıkları belirtilebilir. Ancak çalışmada okumaya soru sorarak başlama stratejisini hiç kullanmadıkları da belirlenmiştir $(\mathrm{f}=0)$. Bu bulgulara bağlı olarak hazırlık aşamasında derinlemesine bir alt yapı oluşturulamadığı belirtilebilir.

Çalışmada okuma sırası stratejilerinden en çok sözlük, internet, başkasına sorma vb. yollarla bilgi edinme stratejisinin kullanıldığı belirtilmiştir $(\mathrm{f}=18)$. Bu durum, sözlük vb.'nin Türkçe derslerinin temel araçları olmasından kaynaklanabilir. Okuma hızını ayarlama $(\mathrm{f}=13)$, görsellerle anlatma $(\mathrm{f}=7)$ ve dikkatini toplayarak tekrar okuma $(\mathrm{f}=6)$ stratejileri daha az kullanılmıştır.

Not alma, düşünmek için ara verme, çelişen bilgileri gözden geçirme, anlamı tahmin ederek bulma ( $\mathrm{f}=1)$; işaretleyerek okuma, metin üzerinde yoğunlaşma, yüksek sesle okuma, içerik ipuçların kullanma, metinde ileri geri ilişki kurma $(\mathrm{f}=0)$ stratejilerine ilişkin bulgular göz önüne alındığında çalışma grubunun okuma sırasında üstbilişsel stratejileri fazla işletmedikleri belirtilebilir. Bunun sebebi, Türkçe ders ve çalışma kitaplarında metne hazırlık çalışmaları ve metin sonrası etkinlikler yer alırken metnin okunması sırasında üstbilişsel becerileri harekete geçirecek yönlendirici etkinliklerin olmaması olabilir. Çetinkaya Edizer, Dilidüzgün, Ak Başoğul, Karagöz ve Yücelşen (2018) de çalışmalarında, Türkçe ders kitaplarındaki okuma sırası etkinliklerinde üstbilişsel okuma stratejilerine az yer verildiği sonucuna ulaşmışlardır.

Okuma sonrası stratejilere ilişkin bulgulara bakıldığında çalışma grubunun metinle ilgili araştırma yapma $(\mathrm{f}=17)$, ana düşünceyi belirleme $(\mathrm{f}=14)$, metindeki bilgiyi günlük hayatla ilişkilendirme $(\mathrm{f}=13)$, metin hakkında başkalarıla tartışma $(\mathrm{f}=12)$ ve metni yeniden okuma $(\mathrm{f}=9)$ stratejilerini daha çok; özetleme $(\mathrm{f}=4)$, tahminlerinin doğruluğunu kontrol etme $(\mathrm{f}=2)$ ve metni okumayı bitirdikten sonra gözden geçirme $(\mathrm{f}=1)$ stratejilerini çok az 
kullandıkları belirlenmiştir. İçerik amaç uyumunu sorgulama ve metindeki bilgileri eleştirerek değerlendirme stratejilerini ise hiçbir öğrenci kullanmamıştır $(\mathrm{f}=0)$. Bu bulgulara bağlı olarak çalışma grubunun okuma sonrası stratejilerini daha çok kullandıkları belirtilebilir. Ancak eleştirel düşünme boyutunda eksikliklerin olduğu ifade edilebilir. Eleştirel düşünme yorumlama, düzenleme, düzeltme, sorgulama ve sonuç çıkarma gibi zihinsel beceriler barındırmaktadır (Facione, 1990: 4). Bu açıdan katılımcıların üst düzey düşünme becerilerini yeterli kullanmadıkları belirtilebilir.

Araştırma sonuçlarına bağlı olarak üstbilişsel okuma sırası stratejilerini işe koşacak çalışmalara öncelik verilmesi gerektiği belirtilebilir. Ayrıca üstbilişsel okuma stratejilerinin kullanım sıklıkları ve çeşitlerinin öğretim yoluyla arttırılması gerekmektedir. Böylelikle yetkin okurlar olarak strateji kullanımın içselleştirilmesine ve buna bağlı olarak anlama becerisinin geliştirilmesine katkı sağlanabilir. 
EXTENDED ABSTRACT

\title{
Metacognitive Reading Awareness of The Eighth Grade Students
}

\author{
Zeynep Çetinkaya Edizer - Esin Özbilgin \\ Istanbul Cerrahpaşa University - Ministry of National Education
}

Metacognition is related to storage, scanning, monitoring and awareness of knowledge in memory (Flavell, 1979). Therefore, metacognitive reading strategies take place in three stages: "planning, monitoring and evaluation" (Baker and Brown, 1984). In literature, these strategies are defined as before reading, during reading, and after reading. Before reading strategies are those of planning strategies of reading such as determining the purpose of reading, deciding the reading pattern and speed, previewing the text, looking at the headings of the text, scanning the length of the text, predicting, asking questions. Strategies such as taking notes while reading, reading carefully, re-reading, marking, using reference sources, estimating, using clues, predicting grammatical associations, using visual styling are strategies used during reading. After reading strategies are strategies for evaluating the content such as questioning, checking, summarizing, re-reading, criticizing, discussing and responding to questions (Karatay, 2011; Ülper, 2010).

McGuire and Yewchuk (1996) found that gifted primary school students are not sufficient in metacognitive reading strategies. In their study with secondary school students, Berkowitz and Cicchelli (2004) revealed that there is no significant difference between high achieving and underachieving secondary students in terms of frequency of strategy use. Karatay (2007) stated that the use of metacognitive reading strategies of prospective Turkish teachers is in the moderate level. He concluded that the least usage of reading strategies is after reading. Çöğmen (2008) found that the level of usage of reading strategies among students in the faculty of education was "frequently used". She also pointed out that there is a significant positive relationship between the reading strategies usage and 
academic success. Hannah and Shore (2008) found that gifted 11-12th grade students have used more monitoring and evaluation strategies. Topuzkanamış (2009) stated that reading strategies of prospective teachers are in moderate level. In addition, he also found that there is a low but significant correlation between reading comprehension and academic achievement point. Anastasiou and Griva (2009) revealed that good readers in 6th grade students used metacognitive reading strategies more frequently than poor readers did. Çetinkaya Edizer (2015) found that the strategy most frequently used by high achieving and underachieving prospective Turkish teachers was monitoring/regulation. High achieving participants use metacognitive strategies more often than under achieving ones. Fitrisia, Tan and Yusuf (2015), in their study with high school students, concluded that metacognitive reading strategies plays a significant role on comprehension.

In this study, it was aimed to determine the use of metacognitive reading strategies in the eighth-grade students by interview. For this purpose, the answer to this question was sought: "What are the types of metacognitive reading strategies used by eighth grade students and the frequency of use?"

\section{Method}

In this study, a descriptive survey model was used to reveal an existing situation and data were obtained by interview which is a qualitative research technique.

The research group of the study consisted of the 20 students from 8th grade who were educated from 50. Y1l General Refet Bele Secondary School in Kartal/Istanbul in the education year of 2016-2017.

For the research Metacognitive Awareness Reading Skills Interview Form was developed. This form was based on the Metacognitive Awareness Reading Strategies Inventory, developed by Mokhtari and Reichard (2002), which was also adapted to Turkish version in terms of reliability and validity by Öztürk (2012). The 12-itemed interview form was organized by receiving expert opinion. 
Content analysis was conducted on the interview form. A code list has been prepared by examining the literature. The analysis of interview form was performed by two researchers.

\section{Findings, Discussion and Results}

In the study, it was determined that the study group used metacognitive strategies in all three stages before, during and after reading $(f=181)$. However, when the collection was evaluated $(f=660)$, it was seen that the use of metacognitive strategy was low in the study group. In this literature the use of metacognitive reading strategies in primary school (McGuire and Yewchuk, 1996), secondary school (Berkowitz and Cicchelli, 2004) and candidate teachers (Çetinkaya Edizer, 2015; Karatay, 2007; Topuzkanamıs, 2009) were generally found to be medium or low. Depending on these findings at different levels, the use of strategy is not sufficient.

According to the study, it was determined that the study group used the most metacognitive strategies after reading $(f=72)$. This is followed by before reading $(f=60)$ and during reading $(f=48)$ strategies. There are different results regarding to this situation in the literature. Hannah and Shore (2008), eleven and twelfth-grade gifted students during and after reading (monitoring and evaluation); Karatay (2010), six, seven and eighth grade students are before reading (planning); Cetinkaya Edizer (2015) also found that Turkish teacher candidates use during reading (monitoring/regulation) strategies more frequently.

Depending on the results of the research, it can be stated that the studies that will employ the metacognitive reading order strategies should be given priority. In addition, the frequency and types of metacognitive reading strategies should be increased through teaching. Thus, as competent readers, it can contribute to the internalization of strategy usage and the development of understanding skills accordingly.

\section{Kaynakça / References}

Aktürk, A. O. ve Şahin, İ. (2011). Üstbiliş ve bilgisayar öğretimi. Selçuk Üniversitesi Ahmet Keleşoğlu Eğitim Fakültesi Dergisi, 31, 383-407. 
Anastasiou, D.ve Griva, E. (2009), Awareness of reading strategy use and reading comprehension among poor and good readers. Ilköğretim Online, 8(2), 283-297.

Bahar, M.A. (2017). 4MAT öğretim düzenine göre gerçekleştirilen üstbilişsel okuma stratejisini kullanma ve olgusal bilgilendirici metinleri anlama düzeyine etkisi. Yayınlanmamış Doktora Tezi, Gazi Üniversitesi, Ankara.

Başaran, M. 2013. 4. sınıf öğrencilerinin üstbilişsel okuma stratejilerini kullanma durumları ve bu stratejilerle okuduğunu anlama arasındaki ilişki. Turkish Studies, 8 (8), 225-240.

Baker, L. ve Brown, A.L. (1984). Metacognitive skills and reading. P.D. Pearson, R. Barr, M.L. Kamil ve P. Mosenthal (Ed.), Handbook of reading research, (ss. 353-394). New York: Longman.

Berkowitz, E. ve Chiccelli, T. (2004). Metacognitive strategy use in reading of gifted high achieving and gifted underachieving middle school students in New York City. Education and Urban Society, 37(1), 3757.

Bilgin, N. (2000). İçerik analizi. İzmir: Ege Üniversitesi Edebiyat Fakültesi Yayınları.

Büyüköztürk, Ş., Kılıç Çakmak, E., Akgün, Ö. E., Karadeniz, Ş. ve Demirel, F. (2014). Bilimsel araştırma yöntemleri. Ankara: Pegem Yayıncılık.

Çakıroğlu, A. (2007). Üstbiliş. Türkiye Sosyal Araştırmalar Dergisi, 2, 22-26.

Çetinkaya Edizer, Z. (2015). An analysis of prospective Turkish teachers' metacognitive reading strategy use. Anthropologist, 22(2), 249-256.

Çetinkaya Edizer, Z., Dilidüzgün, Ş., Ak Başoğul, D., Karagöz, M. ve Yücelşen, N. (2018). Türkçe ders kitaplarındaki okuma etkinliklerinde kullanılan üstbilişsel okuma stratejileri ile okuma yöntemtekniklerinin metin türüne uygunluk bağlamında değerlendirilmesi. Ders Kitapları Uluslararası Sempozyumu (ss.140-141). İstanbul: Yıldız Teknik Üniversitesi.

Çöğmen, S. (2008). Ĕ̆itim fakültesi öğrencilerinin kullandıkları okuduğunu anlama stratejileri. Yayınlanmamış Yüksek Lisans Tezi, Adnan Menderes Üniversitesi, Aydın. 
Facione, P. A. (1990). Critical thinking: a statement of expert consensus for purposes of educational assessment and instruction - executive summary - the delphi report. Millbrae CA: The California Academic Pres.

Fitrisia, D., Tan, K. ve Yusuf, Y. Q. (2015). Investigating metacognitive awareness of reading strategies to strenghthen students'performance in reading comprehension. Asia Pacific Journal of Educators and Education, 30, 15-30.

Flavell, J. H. (1979). Metacognition and cognitive monitoring: a new area of cognitive devolopment inquiry. American Psycologyist, 34, 906911.

Hannah, C. I. ve Shore, B. M. (2008). Twice-exceptional students' use of metacognitive skills on a comprehension monitoring task. Gifted Child Quarterly, 52 (1), 3-18.

Jacopson, R. (1998). Teachers improving learning using metacognition with self-monitoring learning strategies. Education, 118 (4), 579589.

Karatay, H. (2007). İlköğretim Türkçe öğretmeni adaylarının okuduğunu anlama becerileri üzerine alan araştırması. Yayınlanmamış Doktora Tezi, Gazi Üniversitesi, Ankara.

Karatay, H. (2010). İlköğretim öğrencilerinin okuduğunu kavrama ile ilgili bilişsel farkındalıkları. Türklük Bilimi Araştırmaları, 27, 457-475.

Karatay, H. (2011). Okuma eğitimi kuram ve uygulama. Ankara: Berikan Yayınevi.

McGuire, L. ve Yewchuk, C. R. (1996). Use of metacognitive reading strategies by gifted learning disabled students: an exploratory study. Journal for the Education of the Gifted, 19 (3), 293-314.

Merriam, S.B. (2013). Nitel araştırma desen ve uygulama için bir rehber. (Çev.Editörü: Selahattin Turan). Ankara: Nobel Yayınları.

Mokhtari, K ve Reichard, C. A. (2002) Assesing students' metacognitive awareness of reading strategies. Journal of Educational Psychology, 94, 249-259.

Özdemir, S. (2018). The effect of summarization strategies teaching on strategy usage and narrative text summarization success. Universal Journal of Educational Research, 6 (10), 2199-2209. 
Özek, Y. ve Civelek, M. (2006). A study on the use of cognitive reading strategies ELT sudents. The Asian EFL Journal, 14, 1-26.

Özsoy, G. (2008). Üstbiliş. Türk Ĕgitim Bilimleri Dergisi, 6(4), 713-740.

Öztürk, E. (2012). Okuma stratejileri üstbilişsel farkındalık envanterinin Türkçe formunun geçerlik ve güvenirlik çalışması. İlköğretim Online, 11(2), 292-305.

Schraw, G. ve Moshman, D. (1995). Metacognitive theories. Educational Psychology Review, 7(4), 351-371.

Topuzkanamış, E. (2009). Öğretmen adaylarının okuduğunu anlama ve okuma stratejilerini kullanma düzeyleri. Yayınlanmamış Yüksek Lisans Tezi, Balıkesir Üniversitesi, Balıkesir.

Ülper, H. (2010). Okuma ve anlamlandırma becerilerinin kazandırılması. Ankara: Nobel Yayın Dağıtım.

Yaylı, D. (2010). A think-aloud study: cognitive and metacognitive reading strategies of ELT department students, Ĕ̆gitim AraştırmalarıEurasian Journal of Educational Research, 38, 234-251.

Yıldırım, A. ve Şimşek, H. (2013). Sosyal bilimlerde nitel araştırma yöntemleri. Ankara: Seçkin Yayıncılık.

\section{Kaynakça Bilgisi / Citation Information}

Çetinkaya-Edizer, Z. ve Özbilgin, E. (2019). Sekizinci sınıf öğrencilerinin üstbilişsel okuma farkındalıkları. OPUS-Uluslararası Toplum Araştırmaları Dergisi, 10(17), 154-175. DOI: 10.26466/opus.501825 